\title{
Effect of Melt Temperature on Weld Line Strength
}

\author{
Karel Raz ${ }^{1, a}$, Frantisek Sedlacek ${ }^{1, b}$ \\ ${ }^{1}$ Regional Technological Institute, Faculty of Mechanical Engineering, University of West Bohemia, \\ Univerzitni 8, 30614 PIzen, Czech Republic \\ akraz@rti.zcu.cz, afsedlace@rti.zcu.cz
}

Keywords: Strength, Weld line, Injection molding, Specimen, Temperature

\begin{abstract}
This article deals with the influence of the melt temperature on weld line strength in injection-molded plastic parts. A special mold was created for this investigation to make specimens with a central weld line. The experimental material was polypropylene Sabic PP 90910. Its stress at break is around $16 \mathrm{MPa}$ and its melting temperature is between $200^{\circ} \mathrm{C}$ and $260^{\circ} \mathrm{C}$. In general, the presence of weld lines has a negative impact on mechanical properties. This investigation showed that the strength depends on the melt temperature $\left(160-260^{\circ} \mathrm{C}\right.$ in this case). Strength was measured using mechanical testing. It was found to increase with the melt temperature, up to $210^{\circ} \mathrm{C}$. Above $210^{\circ} \mathrm{C}$, degradation of the plastic led to decreasing strengths. A melt temperature range of $190-210^{\circ} \mathrm{C}$ is therefore optimal for this application. Shear forces and friction were found to play a great role, as they raise the melt temperature during molding. This was confirmed by mold-flow analysis. The melt temperature during molding was up to $18 \%$ higher than the initial melt temperature. This investigation has important consequences for the plastic industry. It is relevant to evaluations of the polymer matrix strength in composite materials and the strength of $3 \mathrm{D}$ printed parts with multiple weld lines.
\end{abstract}

\section{Introduction}

Plastic injection molding is one of the most widely-used production methods. The process of designing plastic parts differs from that for metal ones. This difference is sometimes neglected, which can lead to product damage. Weld lines in plastic parts are one of specific occurrences in this respect. They tend to impair the strength of material. [1]

This paper builds on previous research in which the effects of weld lines on material properties were explored in great depth [2]. Yet, it is necessary to characterize this aspect more thoroughly with respect to the melt front temperature.

The resultant data can be useful for various fields, such as injection molding, processing of composite materials and evaluating the properties of polymer matrices. It is most relevant for 3D printing, a process which produces numerous weld lines (Fig. 1). [3, 4]

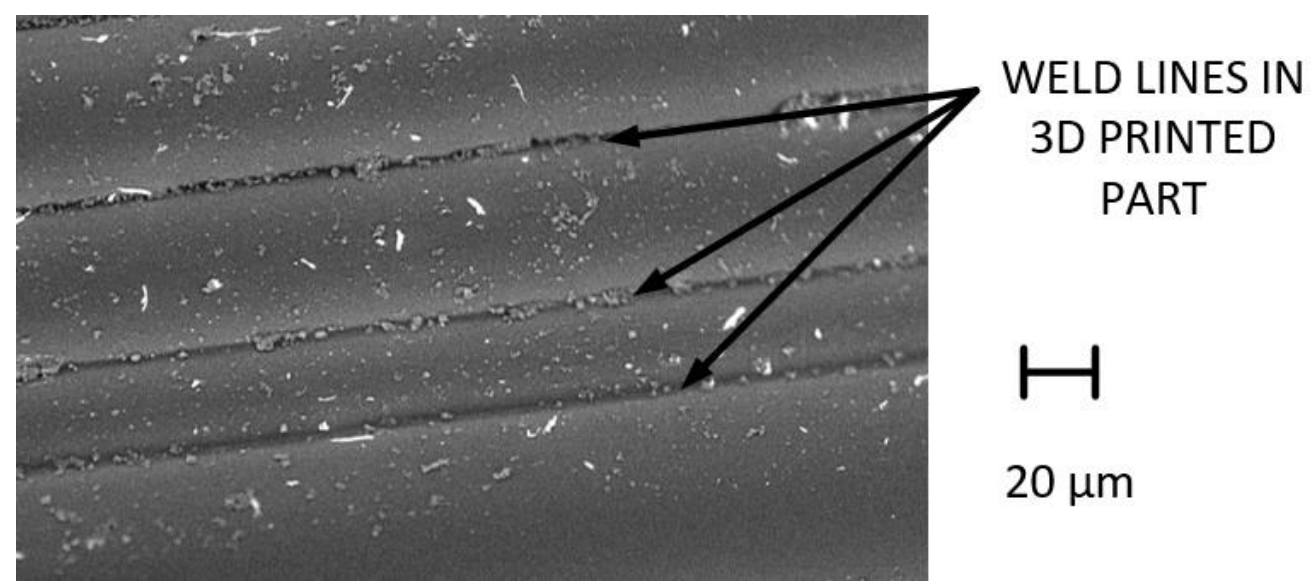

Fig. 1. Weld lines in a 3D printed part from plastic material 
3D printing is a modern additive manufacturing process for making solid parts which relies on CAD (Computer Aided Design) files. It involves adding layers of material along a pre-defined path. Each layer has the form of a horizontal cross-section through the final product. Weld lines are thus produced between the consecutive layers [5]. With this technology, it is difficult to predict the resultant mechanical properties, as they depend on the weld line strength and orientation. This paper helps to understand the weld line behavior. $[6,7]$

\section{Production and mechanical testing of specimens}

A special mold was developed and manufactured for this investigation (Fig. 2). The products are specimens with and without a central weld line. The ones without the weld line were not used for this research. Sabic PP 90910 polypropylene was used as the experimental material. It has widespread use in the automotive industry, especially for making car bumpers. It is a polypropylene copolymer resin with a declared stress at break of $16 \mathrm{MPa}$. As the specimens were produced, the melt temperatures at gate ranged from $160^{\circ} \mathrm{C}$ to $260^{\circ} \mathrm{C}$. This range was chosen with respect to the recommended temperatures for this material $\left(200-260^{\circ} \mathrm{C}\right)$ and also with respect to the molding press (a small experimental device Babyplast 6/10P). The melt temperature in the mold cavity also depends on shear rate and friction. These cause temperature to increase, as evidenced by numerical simulation. To compensate for this increase, the melt temperatures used were lower than the minimal temperature given in the material data sheet $\left(200^{\circ} \mathrm{C}\right)$. [8, 9]

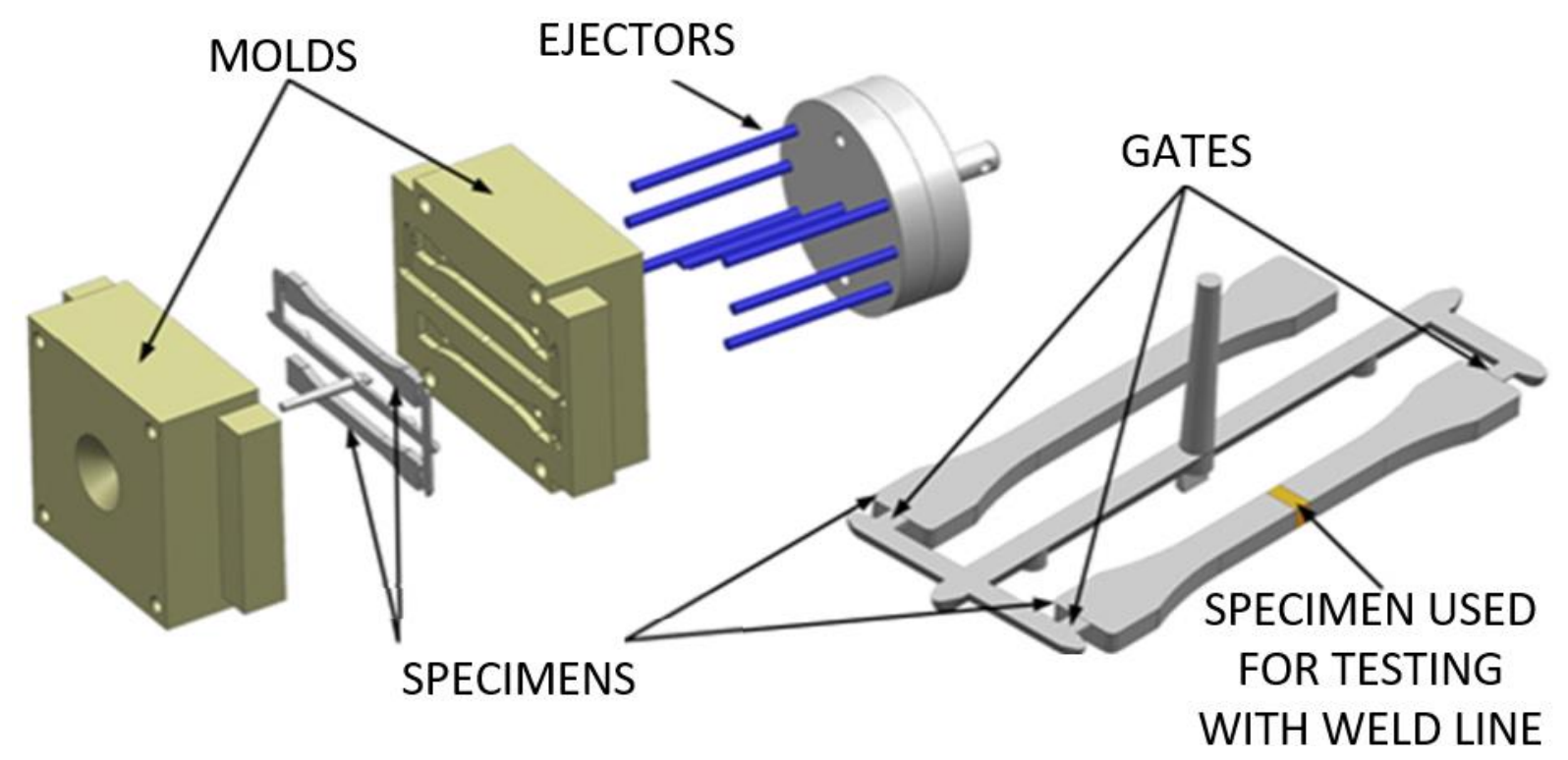

Fig. 2. Mold design with plastic specimens (only the specimen with the weld line was used for investigation)

Five specimens according Fig.3 were made with each melt temperature and tested. Real specimens are shown in Fig. 4. The resultant strength values reported are average values from these five specimens.

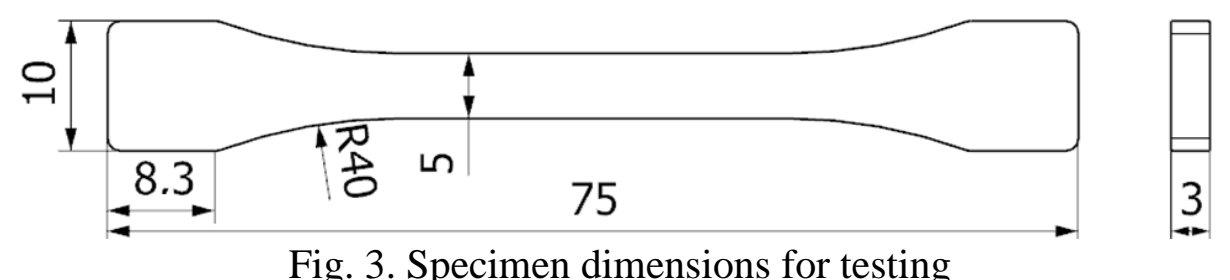

Fig. 3. Specimen dimensions for testing 


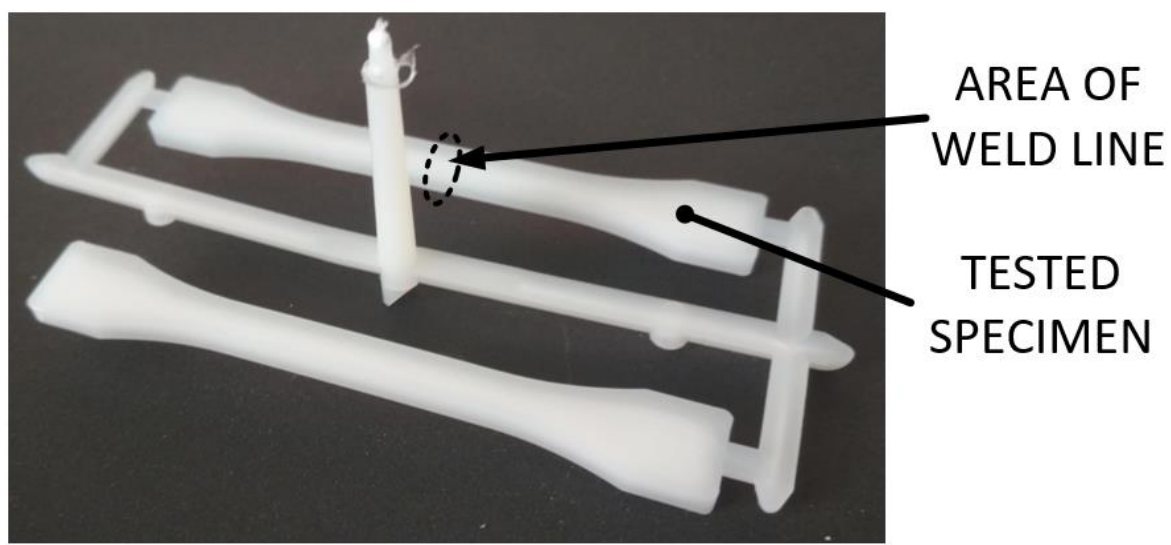

Fig. 4. Photograph of actual specimens

The weld line strength increases according Tab. 1 with the melt temperature up to $210^{\circ} \mathrm{C}$. Beyond this point, strength begins to decrease significantly. The position of this point strongly depends on the material and the mold design. Between $190^{\circ} \mathrm{C}$ and $210^{\circ} \mathrm{C}$, the weld line strength can be considered constant.

Table 1. Relationship between melt temperature and weld line strength

\begin{tabular}{|l|r|r|r|r|r|r|r|r|r|r|r|}
\hline T melt $\left[{ }^{\circ} \mathrm{C}\right]$ & 160 & 170 & 180 & 190 & 200 & 210 & 220 & 230 & 240 & 250 & 260 \\
\hline Strength $[\mathrm{MPa}]$ & 11.83 & 12.06 & 12.50 & 13.00 & 13.12 & 13.13 & 12.61 & 12.28 & 11.94 & 11.76 & 11.59 \\
\hline
\end{tabular}

The relationship is plotted in Graph 1. The maximum strength is only attained within a narrow temperature range. The measured difference in weld line strength is up to $12 \%$ with respect to melt temperature. This strength profile can be described using a third-order polynomial trend line, as shown in Graph 1 (dotted line).

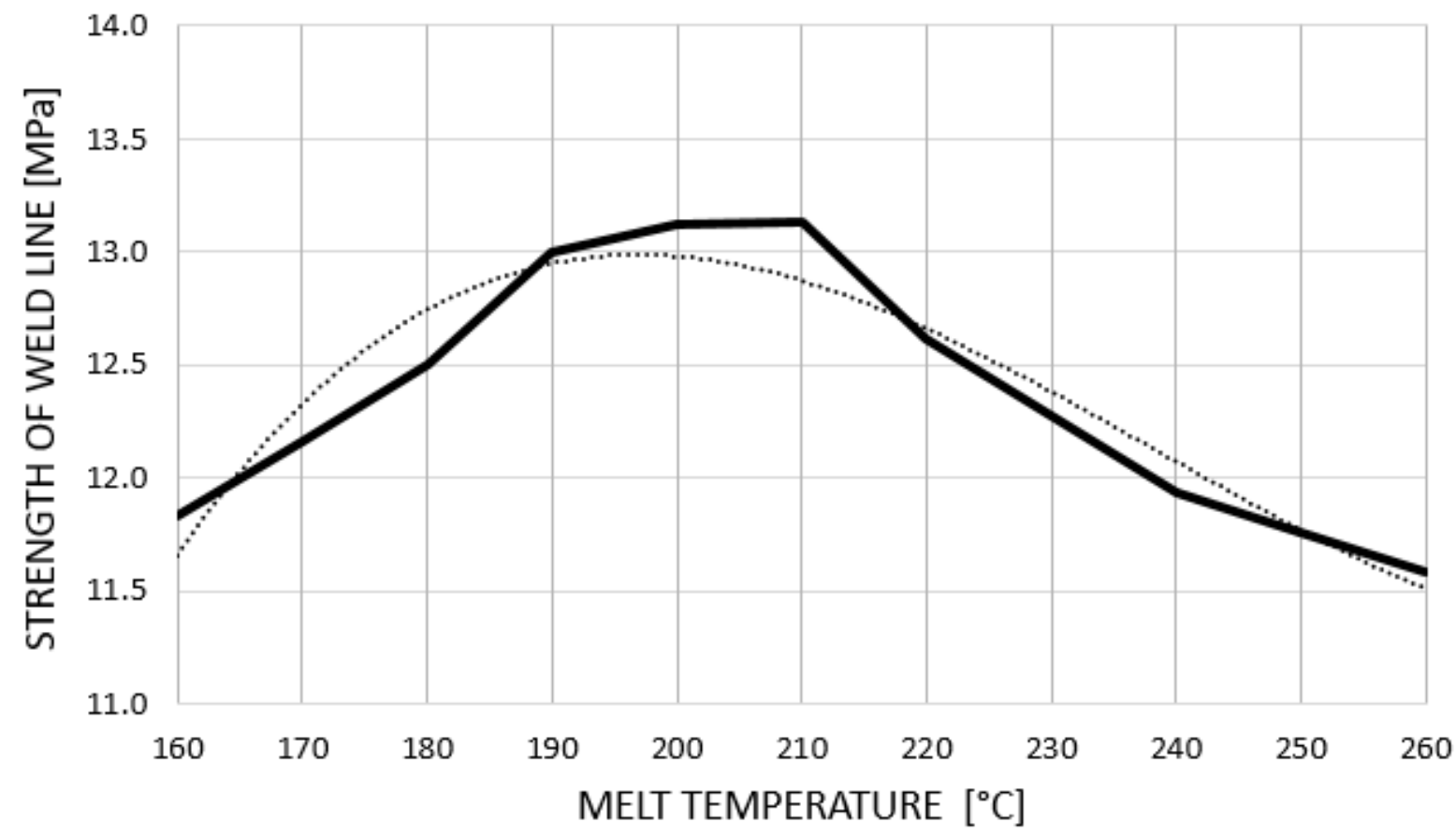

Graph 1: Relationship between melt temperature and strength of weld line, and a third-order polynomial trend line 


\section{Virtual validation of weld line strength by mold flow analysis}

Several mold flow analyses were performed using Moldex 3D software. This software is one of the most widely used tools for mold flow simulations. FEM mesh was created by usage of Siemens NX 11 tool. This mesh is consisted from tetrahedral elements with midnodes in amount more than 2 millions. Higher number of elements leads to more accurate results in mold flow analysis. By this means, it is possible to determine influence of melt temperature on mechanical properties of plastic part.

Analysis of weld line temperature. The reduction in strength is caused by a rise in temperature during injection molding. Strengths decreased when the maximum temperature reached $230^{\circ} \mathrm{C}$. The temperature at which the weld line is created (Table 2 and Fig. 5) is an important value for strength evaluation. Clearly, the optimal temperature of the melt front, where the weld line forms, is in the range of $212.8^{\circ} \mathrm{C}-230.6^{\circ} \mathrm{C}$.

Table 2. Relationship between melt temperature and weld line temperature

\begin{tabular}{|l|r|r|r|r|r|r|r|r|r|r|r|}
\hline T melt $\left[{ }^{\circ} \mathrm{C}\right]$ & 160 & 170 & 180 & 190 & 200 & 210 & 220 & 230 & 240 & 250 & 260 \\
\hline T weld line $\left[{ }^{\circ} \mathrm{C}\right]$ & 182.4 & 193.3 & 204.1 & 212.8 & 221.4 & 230.6 & 239.7 & 257.2 & 274.8 & 283.2 & 293.1 \\
\hline
\end{tabular}

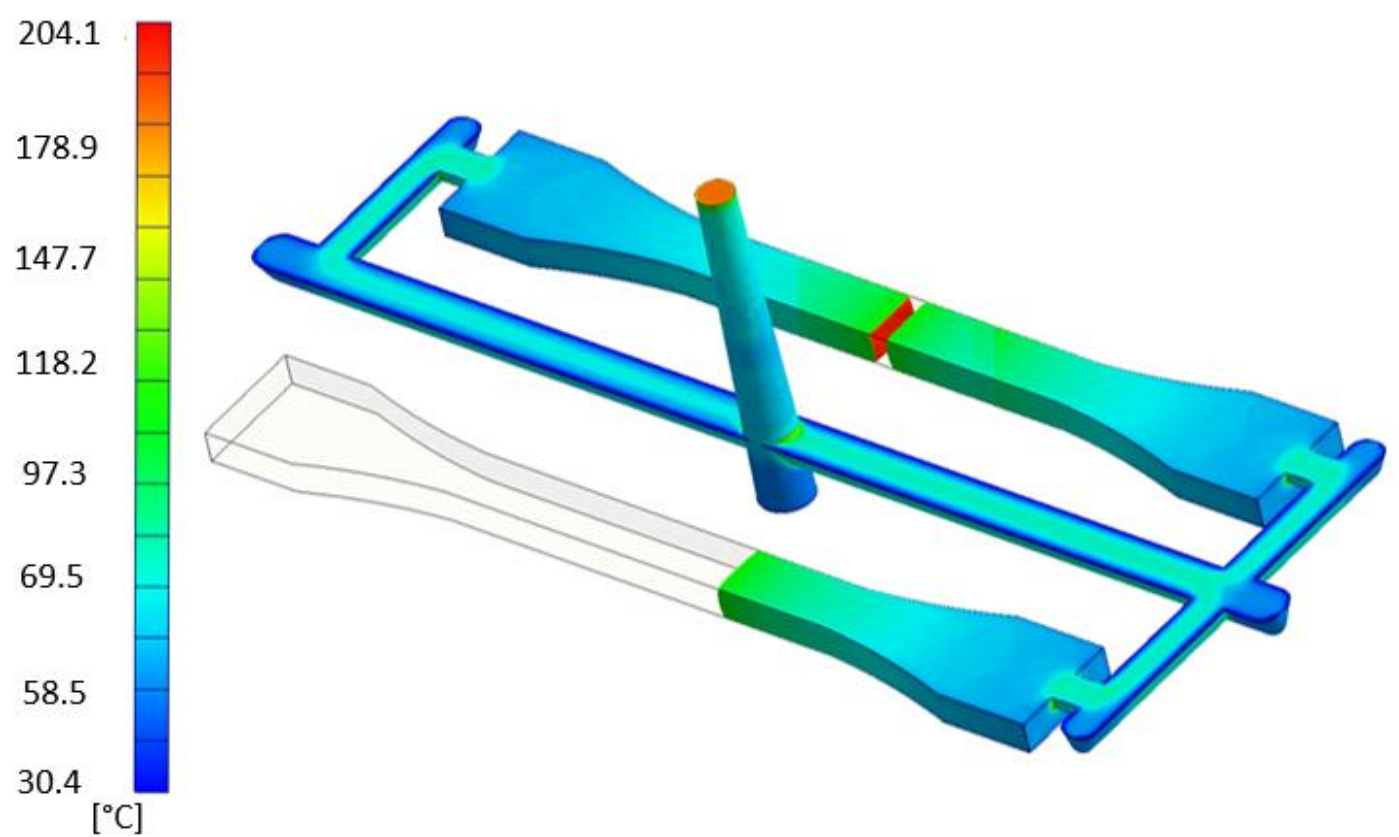

Fig. 5. Temperature distribution at melt temperature of $180^{\circ} \mathrm{C}$

Analysis of maximal temperature during molding process. The rising temperature during molding is obvious from Fig. 6. The figure shows maximal temperatures during the molding process for each point of specimen. They are up to $18 \%$ higher than the initial melt temperature. This is caused by internal friction forces in the melted material. Maximal temperatures during molding must be controlled because they influence mechanical properties of final product. The temperature has to be set up correctly in real production. Inappropriate shape of design can cause temperature increasing (despite the melt temperature is according material list) and this can lead to thermal degradation of material. 


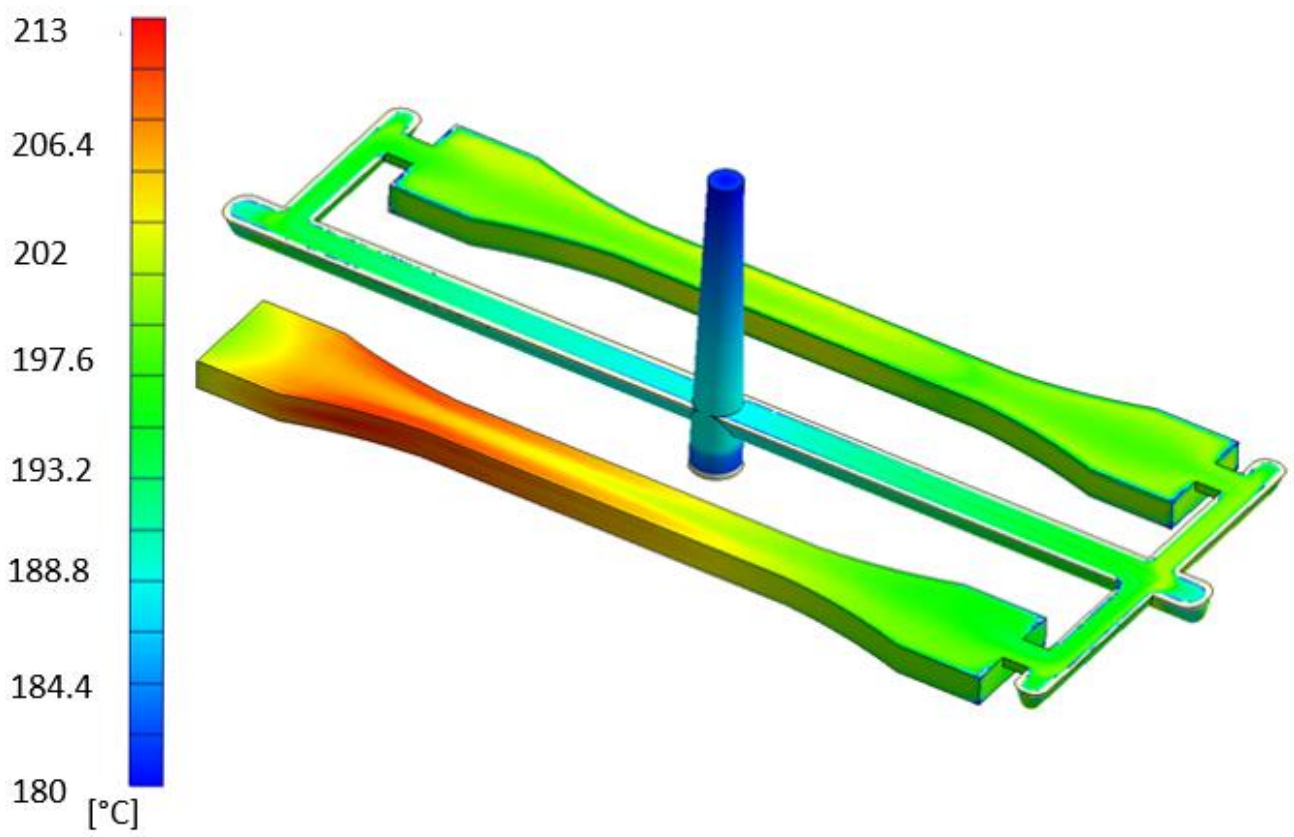

Fig. 6. Maximal temperatures at melt temperature of $180^{\circ} \mathrm{C}$

\section{Conclusion}

This article deals with injection molding problems. It is focused on the influence of the melt temperature on mechanical properties of a molded part of the material polypropylene Sabic PP 90910. In this investigation, negative influence of weld lines on mechanical properties was described. The strength of material was $30 \%$ less than the value declared in the material data sheet. The melt temperature chosen for injection molding of specimens was in the range of $160^{\circ} \mathrm{C}-260^{\circ} \mathrm{C}$. Strength was increasing with the melt temperature up to $210^{\circ} \mathrm{C}$. At higher temperatures, strengths decreased again. The resultant strength was $70-83 \%$ of the declared value. Two methods were used for the evaluation. Findings from mechanical tests were confirmed by mold-flow simulations using software Moldex 3D.

The next steps in this research will involve testing other plastic materials and developing a mold with a reduced influence of its design. Temperature changes during molding process need to be analysed in following research. These results can be used in area of injection molding and at the same time are usable in additive technologies such as 3D print of plastic products, where is produced large amount of welded lines

\section{Acknowledgement}

This paper has been prepared under project LO1502 'Development of the Regional Technological Institute' under the auspices of the National Sustainability Programme I of the Ministry of Education youth and sport of the Czech Republic aimed at supporting research, experimental development and innovation.

\section{References}

[1] S. Rusnakova, A. Capka, L. Fojtl, M. Zaludek, V. Rusnak: Technology and Mold Design for Production of Hollow Carbon Composite Parts, In: Manufacturing Technology, Vol. 16, pp. 799-804, ISSN 1213-2489. (2016).

[2] K. Raz, M. Zahalka: Tensile strength of various nylon PA6 specimen modes, In: AIP Conference Proceedings, Vol. 1846, ISSN 0094243X, ISBN 978-073541518-8. (2017). 
[3] S.H.Tang: Design and thermal analysis of plastic injection mold, In: Journal of Materials Processing Technology. Switzerland, (2006).

[4] J. Cop, L. Fojtl, O. Bilek, V. Pata: Influence of Finishing Operations and Melt Flow Index on Surface Quality of Injection Molded Parts, In: Manufacturing Technology, Vol. 16, pp. 336-338, ISSN 1213-2489. (2016).

[5] A. Ausperger: Simulation of Deformation and Compression of Fabric During the Back Injection Moulding Process, In: Proceedings of the 22nd International DAAAM Symposium, Vienna, Austria, Volume 22, pp. 1261-1262, ISSN 1726-9679, ISBN 978-3-901509-83-4. (2011).

[6] E. Hnatkova, D. Sanetrik, V. Pata, B. Hausnerova, Z. Dvorak: Mold Surface Analysis after Injection Molding of Highly Filled Polymeric Compounds, In: Manufacturing Technology, Vol. 16, pp. 86-90, ISSN 1213-2489. (2016).

[7] K. Raz, J. Hora, P. Pavlata: Unconventional materials usage in design of vehicle bodies, In: Manufacturing Technology, Vol. 17, pp. 823-827, ISSN 1213-2489. (2017).

[8] I.L. Sandu, F. Stan, C. Fatecau: Study of Flow Font Advancement During Filling Stage of a Spiral Mold, In: Applied Mechanics and Materials, Vol. 371, pp. 534-538, ISSN 1662-7482. (2013).

[9] L. Markovicova, V. Zatkalikova: Composite materials Based on pa Reinforced Glass Fibers, In: Material Today, Vol. 3, pp. 1056-1059, ISSN 2214-7853. (2016).

\section{Authors' background}

\begin{tabular}{|c|l|l|l|}
\hline Your Name & \multicolumn{1}{|c|}{ Title* } & \multicolumn{1}{|c|}{ Research Field } & \multicolumn{1}{|c|}{ Personal website } \\
\hline Karel Raz & Lecture & $\begin{array}{l}\text { Virtual simulations, } \\
\text { CAE, plastics, material } \\
\text { testing }\end{array}$ & http://www.zcu.cz/media/about/people/staff.html?osoba=9082 \\
\hline & & & \\
\hline & & & \\
\hline
\end{tabular}

*This form helps us to understand your paper better, the form itself will not be published.

*Title can be chosen from: master student, Phd candidate, assistant professor, lecture, senior lecture, associate professor, full professor 